\title{
Study of Behavior of Human Capital from a Fractal Perspective
}

\author{
Leydi Z. Guzmán-Aguilar ${ }^{1}$, Ángel Machorro-Rodríguez ${ }^{2}$, Tomás Morales-Acoltzi ${ }^{3}$, Miguel Montaño-Alvarez ${ }^{1}$, \\ Marcos Salazar-Medina ${ }^{2} \&$ Edna A. Romero-Flores ${ }^{2}$ \\ ${ }^{1}$ Maestría en Ingeniería Administrativa, Tecnológico Nacional de México, Instituto Tecnológico de Orizaba, \\ Colonia Emiliano Zapata, México \\ ${ }^{2}$ División de Estudios de Posgrado e Investigación, Tecnológico Nacional de México, Instituto Tecnológico de \\ Orizaba, Colonia Emiliano Zapata, México \\ ${ }^{3}$ Centro de Ciencias de la Atmósfera, UNAM, Circuito exterior, CU, CDMX, México \\ Correspondence: Leydi Z. Guzmán-Aguilar, Maestría en Ingeniería Administrativa, Tecnológico Nacional de México, \\ Instituto Tecnológico de Orizaba, Ver. Oriente 9 No. 852 Colonia Emiliano Zapata, C.P. 94320, México. Tel: \\ 1-272-725-7518.
}

Received: November 11, 2016

Accepted: November 27, 2016

Online Published: January 4, 2017

doi:10.5430/ijba.v8n1p50

URL: http://dx.doi.org/10.5430/ijba.v8n1p50

\begin{abstract}
In the last decade, the application of fractal geometry has surged in all disciplines. In the area of human capital management, obtaining a relatively long time series (TS) is difficult, and likewise nonlinear methods require at least 512 observations. In this research, we therefore suggest the application of a fractal interpolation scheme to generate ad hoc TS. When we inhibit the vertical scale factor, the proposed interpolation scheme has the effect of simulating the original TS.
\end{abstract}

Keywords: human capital, wage, fractal interpolation, vertical scale factor

\section{Introduction}

In nature, irregular processes exist that by using Euclidean models as their basis for analysis, do not capture the variety and complexity of the dynamics of their environment. Owing to the need to develop methods more aligned to this behavior, Mandelbrot used a different approach to understand these irregularities in nature, consisting of fragments known as fractals (Mandelbrot, 1997). Use of the fractal geometric approach has grown exponentially over the past two decades. Its application ranges from economics (Mandelbrot, 1997), music (Perez, 2000), medicine (De la Rosa-Orea, 2014), topology (Vivas, 1999), physics (Aguirre 2004), astronomy (Martinez, 1999), meteorology (Morales-Acoltzi, 2015) and geology (Esper, 2005); recently, it has also been successfully introduced to the social sciences, for example psychology (Pestana, 1999), and more so, in everyday life it can be effectively applied to describe nature which surrounds us. In in the last decade, fractal geometry has been explicitly included in sciences of economic administration, as well as in areas of organization and business management, illustrating to entrepreneurs how company behavior is similar to that of a living entity which adapts to its environment (Iturriaga \& Jovanovich, 2014). The human factor is the main element in management decisions. Because human capital is analyzed qualitatively, quantitative models have been proposed, such as that put forward by Iwamoto \& Takahashi (2015) with data from their own company.

In the second section of the study, the theoretical foundations of fractal geometry are presented. In the third section, we describe the database and methodology. The fourth section includes numerical experiments, results and conclusions.

\section{Theoretical Basis}

The fractal approach comprises a modern mathematical area that improves on Euclidean geometry, describing irregularities in nature in terms of fragments that give rise to fractals. Auto-similarity and the fractal dimension are the main features (Williams, 1997). The first indicates that each entity retains the same format as its global characteristics. Fractals manifest an incomplete dimension which surpasses the topology of the figure under study (Braña, 2003), enabling a better description of the processes of nature. Two methods can be used to describe these; repeating a linear fractal process, and applying complex nonlinear fractal numbers, (Mandelbrot, 1997). 
The main precursors of fractal theory were Cantor, Mandelbrot, Lyapunov, Giuseppe Peano, Sierpinski, Helge von Koch and Gaston Julia, some of whom contributed to this notion, prior to the establishment of fractals as currently understood. Their main contributions are explained in Table 1.

Table 1. Main precursors

\begin{tabular}{|c|c|c|}
\hline Author & Contribution & Content \\
\hline Georg Cantor, & Cantor set & $\begin{array}{l}\text { - Take the interval }[0,1] \text {, in each iteration, eliminate the segment } \\
\text { corresponding to the central third of each interval. }\end{array}$ \\
\hline Benoît Mandelbrot, & Mandelbrot set & $\begin{array}{l}\text { - It is the most well-known fractal, uses a combination of a real } \\
\text { number with a complex number. }\end{array}$ \\
\hline $\begin{array}{l}\text { Aleksandr } \\
\text { Liapunov }\end{array}$ & $\begin{array}{l}\text { Markus-Lyapunov } \\
\text { fractals }\end{array}$ & $\begin{array}{l}\text { Contains topological and qualitative changes called bifurcations, } \\
\text { derived from the logistic map, where the degree of growth changes } \\
\text { periodically between two established values. The Lyapunov exponent } \\
\lambda \text { is used. }\end{array}$ \\
\hline Giuseppe Peano & Peano curve & $\begin{array}{l}\text { - Curve covering an area, which is obtained by an iteration, to } \\
\text { form a continuous curve converging to a boundary curve. } \\
\text { - It is a special fractal, because its topological dimension is one } \\
\text { and its fractal dimension } 2 \text {, which although they are integers is } \\
\text { considered a fractal. }\end{array}$ \\
\hline $\begin{array}{l}\text { Wacław Franciszek } \\
\text { Sierpinski }\end{array}$ & Sierpinski curve & $\begin{array}{l}\text { - It is constructed from a triangle, by means of homotecia, centered } \\
\text { in the vertices of the triangle with a ratio of } 1 / 2 \text {. It is similar to the set of } \\
\text { Cantor. }\end{array}$ \\
\hline Helge von Koch & Koch curve & $\begin{array}{l}\text { - Continuous fractal curve that has no tangents, is obtained by } \\
\text { methods of elementary geometry. } \\
\text { - It is constructed by iterations where a line is divided into three, in } \\
\text { the middle segment two more segments are inserted as an equilateral } \\
\text { triangle. }\end{array}$ \\
\hline $\begin{array}{l}\text { Gaston } \\
\text { Julia }\end{array}$ & Julia set & $\begin{array}{l}\text { - Family of fractal sets, obtained by studying the behavior of } \\
\text { complex numbers that are iterated by functions with a restriction to } \\
\text { real numbers. }\end{array}$ \\
\hline
\end{tabular}

Source: Mandelbrot, 1983; Cantor, 1884; Yale, 2016; Flake, 1998

Mandelbrot described a series of problems related to risk and investments, introducing new ideas in different areas of application.

A study by Gálvez Medina E. et al. (2009) showed that fractals are becoming important in decision making. Otherwise, complexity theory is an innovative subject, and fractal structures offer useful applications, such as an increasing the flexibility and adaptability of businesses using them.

Studying quantitative variables that explain economic development can generate scenarios which will facilitate decision-making, thus eliminating biases caused by subjectivism, and increasing the performance and progress of organizational objectives. This can promote: savings, greater knowledge about the company and the establishment of development strategies to increase their competitiveness (Bonatti, 2007). The studies mentioned are concentrated in Table 2.

Table 2. Analysis of previous studies

\begin{tabular}{|c|c|c|}
\hline (Author, year) & Article & Analysis \\
\hline $\begin{array}{ll}\text { Iturriaga } & \& \\
\text { Jovanovich, } & \end{array}$ & Fractals, economy and business & $\begin{array}{l}\text { - It establishes the possibilities of application of fractal } \\
\text { geometry; To the economy, organization and administration }\end{array}$ \\
\hline
\end{tabular}


of companies, analyzing the feasibility of the same.

-Highlights; That by having a greater technological development, companies react more quickly to changes in the environment, this is favorable to detect self-similar patterns at different levels.

\begin{tabular}{|c|c|c|}
\hline $\begin{array}{l}\text { (Iwamoto \& } \\
\text { Takahashi, 2015) }\end{array}$ & $\begin{array}{l}\text { A Quantitative Approach to } \\
\text { Human Capital Management }\end{array}$ & $\begin{array}{l}\text { - Provides a quantitative technique to support decision makers } \\
\text { through the objective assessment of human capital } \\
\text { management. } \\
\text { - The study is carried out in two phases, projecting the } \\
\text { increase of profits generated by the company: } \\
\text { - Selection and formulation of the factors, which are } \\
\text { represented by the main component and its factor analysis. } \\
\text { - Value added is defined, adjusting the index to the } \\
\text { characteristics of the company's personnel and production, } \\
\text { constructing a model to identify the factors of human capital } \\
\text { management, through a multiple regression. }\end{array}$ \\
\hline (Williams, 1997) & Chaos theory tamed. & $\begin{array}{l}\text { - Contains; Antecedents, concepts and characteristics of the } \\
\text { chaos, focused on people without experience in this field. } \\
\text { - Part of simple concepts, to more complex in different areas } \\
\text { of study. }\end{array}$ \\
\hline
\end{tabular}

(Braña, 2003) Notes "Introduction to fractal Contains the historical development on the fractals, explaining geometry" the most known models and their characteristics: self similarity and fractal dimension; Types of fractals (linear and non-linear), as well as the best-known examples.

(Mandelbrot, In Fractals and Scaling in Finance 1997) It shows that the price movement maintains an invariant of scale, manifesting itself from a small period of time (5 minutes), per day and monthly.

- Compares the study with several types of distribution; Random, normal, Brownian.

- Price movement is cyclical, but its length can not be determined over time, this means that it will not be able to decide when it starts and when it ends.

- Models based on current prices do not work in the long term, such as some trend systems.

- It indicates, that to use the indicated mathematical tools, a suitable financial model can be elaborated.

(Gálvez Medina Fractal approach applied in the E. et al. 2009) administration
Shows aspects such as; The evolution of management theories and the versatility of application in the sciences: they favor their integration to explain the applications of the fractal approach in the administration to have matching characteristics.

- Fractal factory. Its objective is the development of companies, adaptable to the metaphor: organizations are living organisms with the possibility to grow and adapt.

- Fractal company. Evolution of the fractal company, applying more coherent knowledge, show results of scientific work and technological developments based on the logic of fractal theory.

\begin{tabular}{lll}
\hline (Bonatti,2007) & $\begin{array}{l}\text { Biases and Pitfalls in Decision } \\
\text { Making }\end{array}$ & $\begin{array}{l}\text { - Explains behaviors, perceptions, and failures that affect } \\
\text { decision making. } \\
\text { • Classify the types of negative behaviors in decision making. }\end{array}$ \\
\hline
\end{tabular}




\section{Data Base}

The study begins with the formation of a database (DB) with a time series for variable "wages". Considering the Monthly Survey of Manufacturing Industry (Encuesta Mensual de la Industria Manufacturera, EMIM), INEGI (2016); for the period January 2007 to December 2015, resulting in a total of 108 observations, the unit of measurement used, involves thousands of pesos. It was calculated from the sum of social benefits, salaries and wages in manufacturing. Using the time series, behavior becomes apparent and it is thus characterized as a "fractal company". The most consistent applications of knowledge are steeped in the logic of the theory of fractals.

\section{Methodology}

A very important issue in the DB is the absence of records, therefore questioning how to complete the TS for the observed variables. The methodology associated with the analysis of non-linear dynamic systems requires at least 512 data, so that in this research we must complete a TS of wages, consisting of only 108 observations, and the challenge is to preserve dynamic characteristics (Barnsley, 2014). Tests were carried out and are explained in the following, in order to simulate the behavior of the "wages" variable, which influences the area of human resources.

In organizations, a situation of non-linearity arises, related to constant feedback, which is independent of external or internal elements, so the use of fractal geometry and non-linear dynamic systems is necessary (Guzman, 2016).

For the purpose of numerical experiments: data is first normalized in order to reduce problems with the relative handling of quantities with many digits. This was undertaken using a method of dividing the TS by the greatest absolute number, thus obtaining numbers ranging between $(0,1]$.

Following Barnsley (2014), the model for fractal interpolation is produced from five equations, the first point relates directly to the observed interpolated point. Five parameters, determined by the equations $2-5$ and by the observed TS, were included.

$$
\begin{gathered}
w_{n}\left(\begin{array}{l}
x \\
y
\end{array}\right)=\left(\begin{array}{ll}
a_{n} & 0 \\
c_{n} & d_{n}
\end{array}\right)\left(\begin{array}{l}
x \\
y
\end{array}\right)+\left(\begin{array}{l}
e_{n} \\
f_{n}
\end{array}\right) \\
a_{n}=\frac{x_{n}-x_{n-1}}{x_{N}-x_{0}} \\
e_{n}=\frac{\left(x_{N} x_{n-1}-x_{N} x_{0}\right)}{x_{N}-x_{0}} \\
c_{n}=\frac{\left(F_{n}-F_{n-1}\right) /\left(x_{N}-x_{0}\right)-d_{n}\left(F_{N}-F_{0}\right)}{x_{N}-x_{0}} \\
f_{n}=\frac{\left(x_{N} F_{n-1}-x_{0} F_{n}\right)}{\left(x_{N}-x_{0}\right)}-d\left(\frac{\left(x_{N} F_{0}-x_{0} F_{N}\right)}{\left(x_{N}-x_{0}\right)}\right)
\end{gathered}
$$

$d_{n}$ represents a vertical scale factor that can be any real number.

$a, c, e, f$ are real numbers, known as a transformation to two dimensions.

\section{Results and Discussion}

In Figure 1, the original series is compared to the standard, in order to verify that the wage variable does not vary. In Figure 1a, a periodic increase is observed. This occurs at the end of each year, rewarding the workers in the form of Christmas bonuses and bonuses for productivity, among other benefits. It also indicates a positive trend in economic conditions in the country, in the form of increases in minimum wage and inflation. 


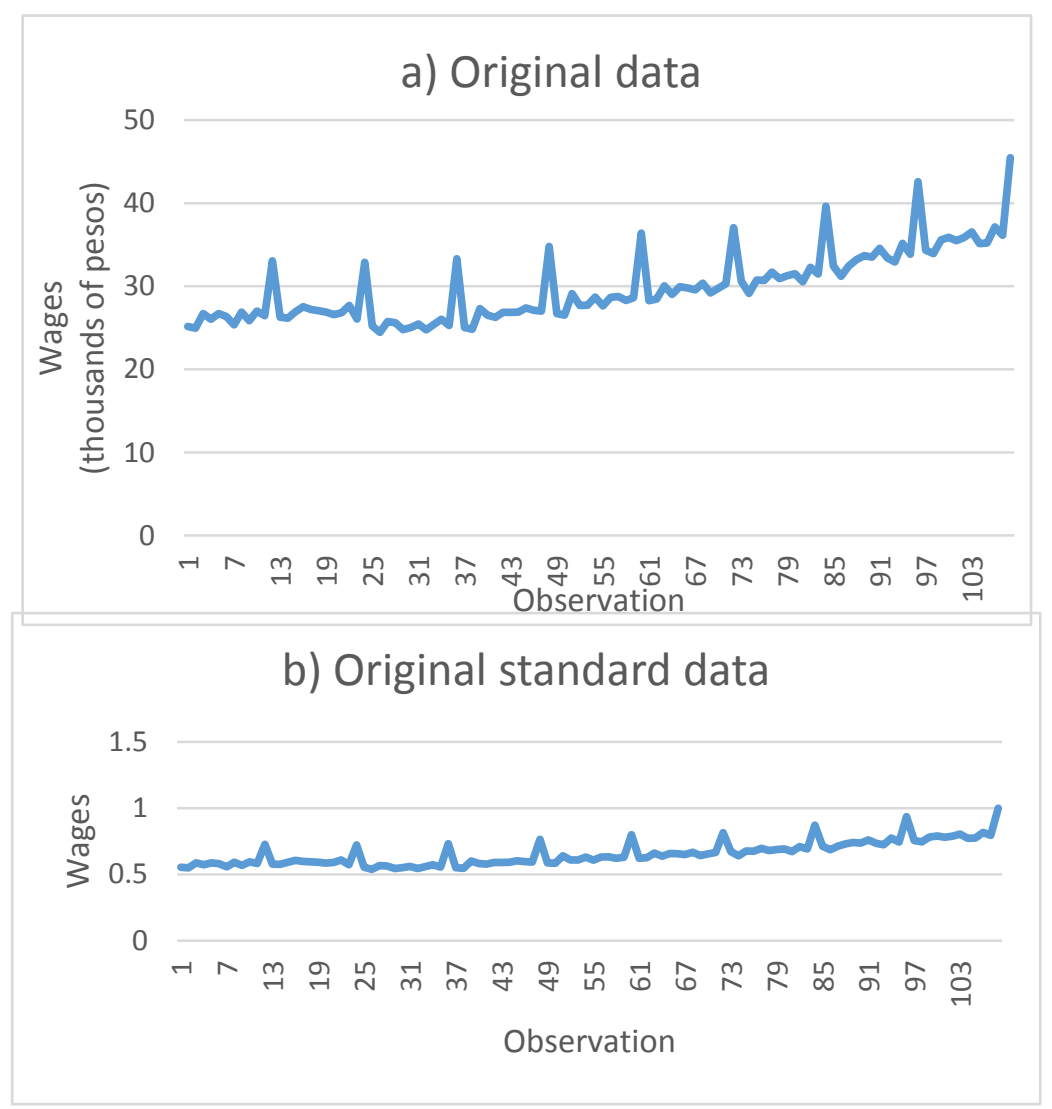

Figure 1 a) Original data series b) Standard data set between 0 and 1

The interpolation was conducted in three phases: firstly, scale invariance (SI) 0.5 was used to increase the frequency of the TS, 2a; secondly, the noise generated by expansion was reduced using a coefficient $-0.5,2 \mathrm{~b}$; and finally 0.23 was employed as $\mathbf{S I}, 2 \mathrm{c}$.

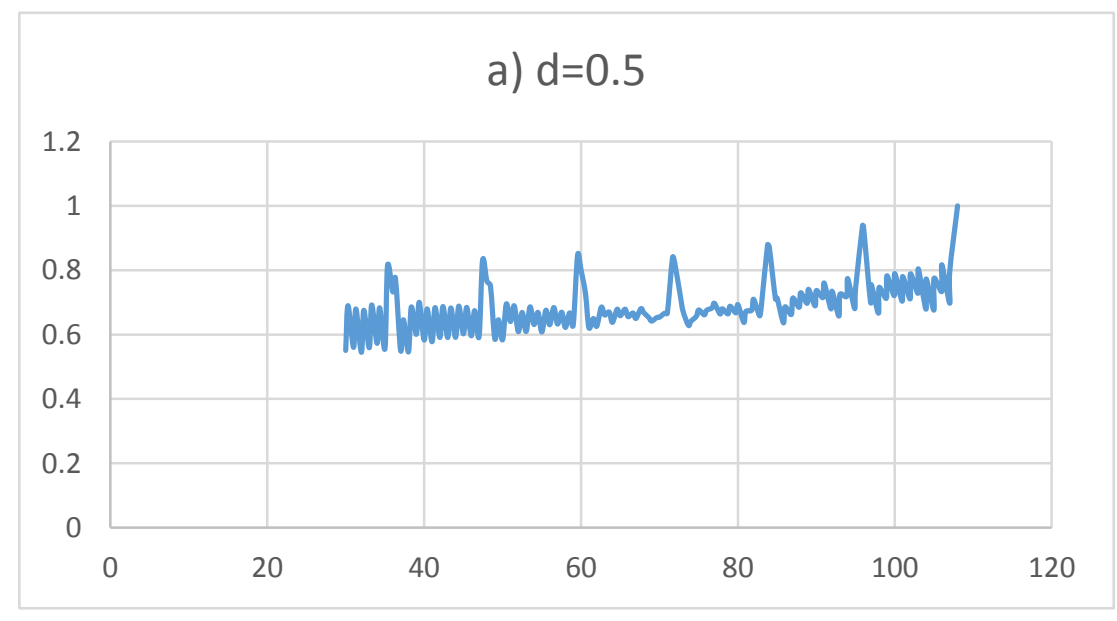




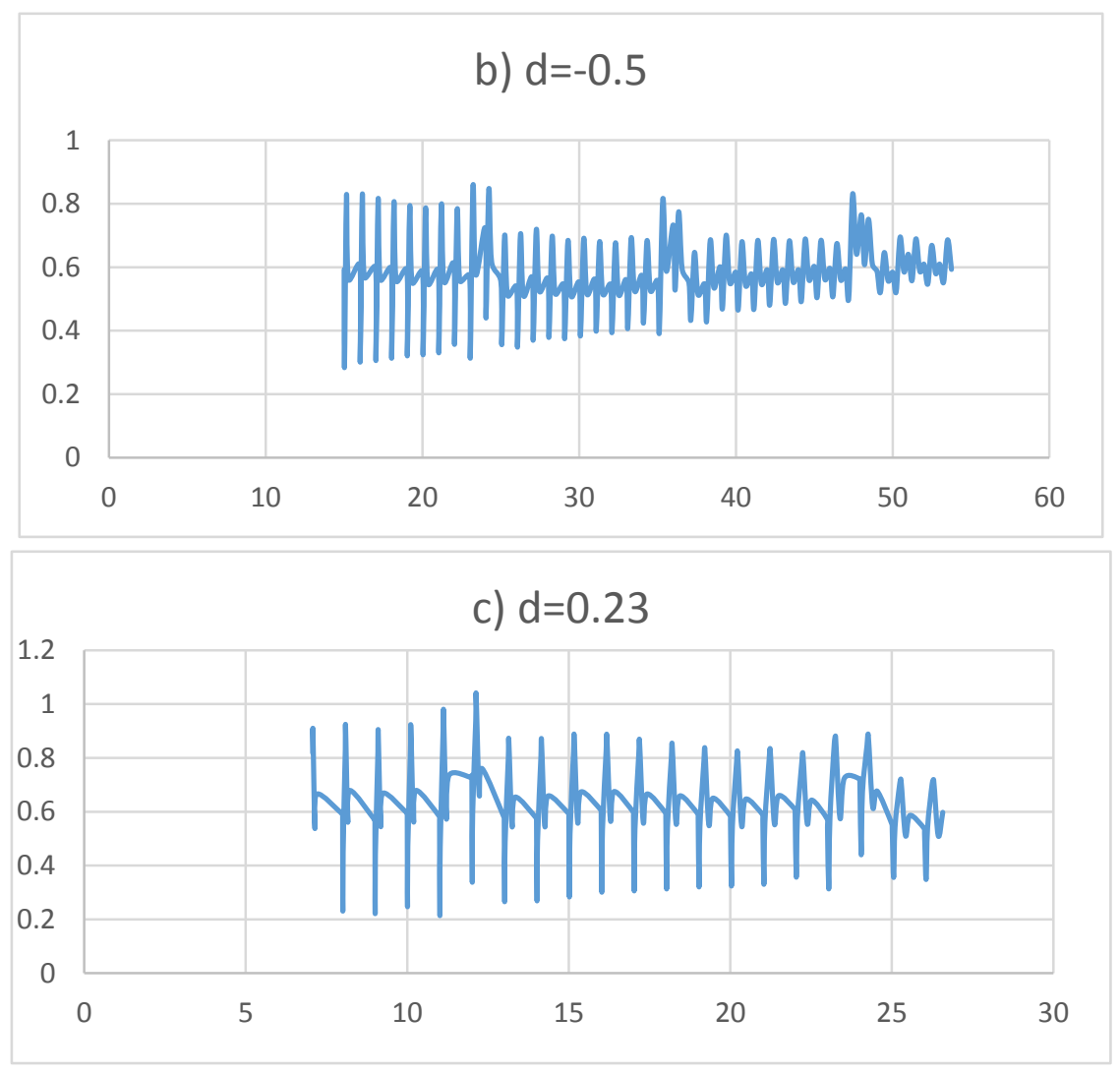

Figure 1. Interpolation phases with standard data

To demonstrate the effect of SI in the interpolation, an experiment was carried out, which only modified to a minimal extent; by hundredths, as shown in Figure 3. This factor modified the behavior of the variable, only influencing the inclination of the abscissa line and controlling the extent of variability.

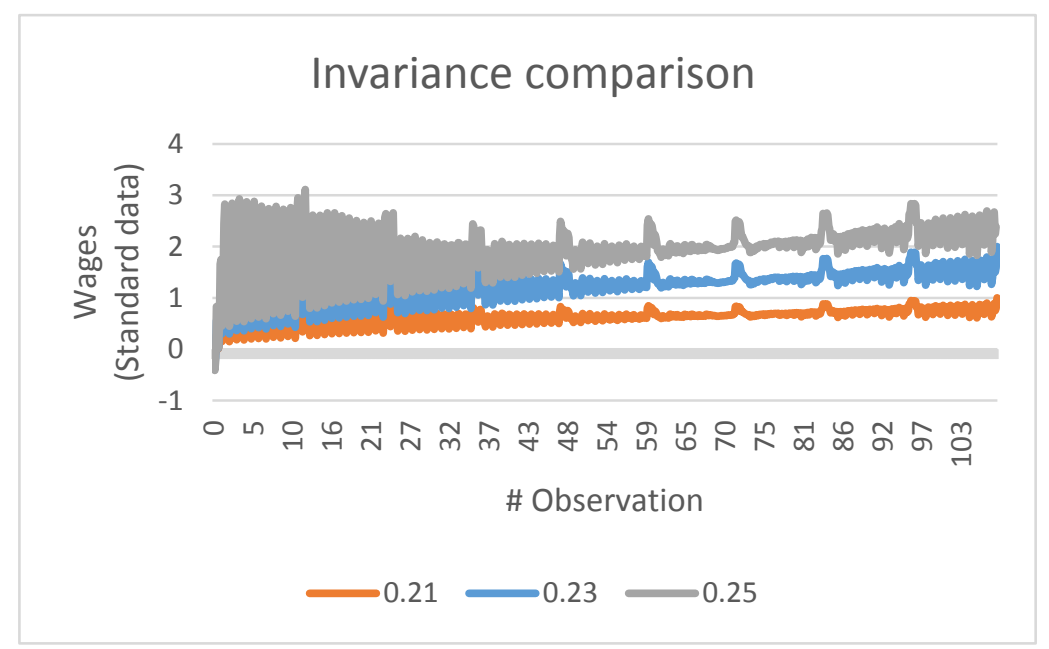

Figure 3. Interpolation phases with standard data

Figure 4 shows that the arithmetic and geometric interpolation, only places some points within the original data, however, the fractal interpolation generates data so that one can observe the natural behavior of the variable being studied; thus if this uses an $\mathbf{S I}=0$, behavior continues perfectly without varying from the original. Thus a test for the proposed interpolation scheme, aims to check whether it recovers or simulates the original data, considering a null SI. 


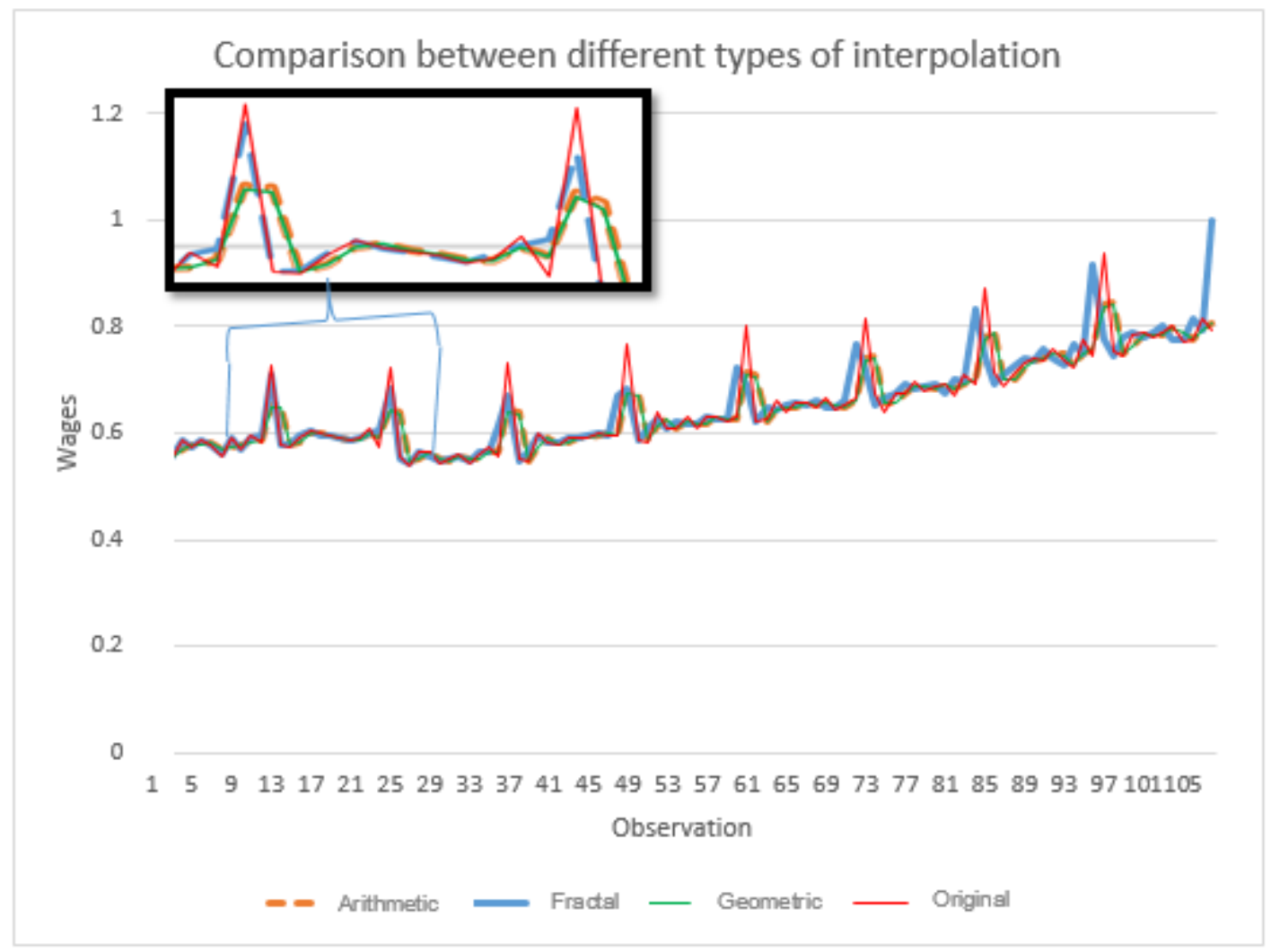

Figure 4. Graph of achieved interpolations

Another numerical experiment that enabled us to meet our goal, involved building a TS with more than 512 values, maintaining the dynamic behavior originally identified.

\section{Conclusions}

When conducting a study with a social component represented by wages, it is generally difficult to have a "complete" DB, which fulfills the requirements of the theory of dynamical systems. It was thus necessary to complete the DB with linear, nonlinear and fractal interpolation schemes. The arithmetic and geometric interpolations attempted to follow the behavior of the system being studied; however, it did not capture all changes contained in the original TS, except for fractal interpolation. In other words, fractal interpolation took advantage of the fact that processes are fractal for showing SI; enabling them to keep the observed dynamic invariants.

After applying fractal theory, one can conclude, that it does not change TS; it is only that the number of observations increases, which was our goal. Likewise fluctuations, and also increases and decreases are respected, including their most drastic variations.

Using this study, we were able to analyze the fractal characteristics of human capital in order to determine the degree of fractality that it contains and thus make correct decisions about the manufacturing sector, complying with results projected for the analysis.

\section{Acknowledgements}

The first author thanks the National Technological institute of Mexico / Technological Institute of Orizaba; CONACyT_Beca-DEPI; CONACyT_ Mobility Scholarship, and the Center for Atmospheric Sciences, UNAM for their support and sponsorship, for the realization of short stays that, thanks to them, helped me to finish this article and to see a new panorama.

Professors Edna Araceli Romero Flores, Ángel Machorro Rodríguez and Marcos Salazar Medina, thank the Coordination of Scientific Research, Academic Secretary, Technical Secretary of Academic Exchange and the National Technological institute of Mexico / Technological Institute of Orizaba, for their support as Visiting 
Professors To the Center for Atmospheric Sciences, UNAM.

\section{References}

Aguirre, J., \& Sanjuán, M. A. (2004). Incertidumbre Clásica, Dispersión Caótica y Estructuras Fractales en Física. Revista Española de Física, 18(3), 23-27.

Barnsley, M.F. (2014). Fractals Everywhere. Academic Press.

Bonatti, P. (2007). Los sesgos y las trampas en la toma de decisiones. Retrieved from http://www.econ.uba.ar/www/institutos/epistemologia/marco_archivos/ponencias/Actas\%20XIII/Trabajos\%20E piste/BONATTI_trabajo.pdf

Braña, J.P. (2003). Notas“ Introducción a la geometría fractal”. Buenos Aires, Argentina. Retrieved from http://www.docentes.unal.edu.co/cibermudezs/docs/CursoGeometriaFractal.pdf

Cantor, G. (1884). De la puissance des ensembles parfaits de points. Acta Mathematica, 4(1), 381-392.

De la Rosa-Orea, G., Medel-Rojas, A., Morales-Acoltzi, T., Ramírez, E.M., López-Oglesby, J.M., \& González-Pérez, M. (2014). Caracterización fractal de angioresonancia magnética cerebral.

Esper, L.B. (2005). Fractales en las Ciencias. Geológicas. Doctoral dissertation, Tesis inédita de maestría. Facultad de Arquitectura y Urbanismo-UNT, Argentina.

Flake, G.W. (1998). The computational beauty of nature: Computer explorations of fractals, chaos, complex systems, and adaptation. MIT press.

Gálvez, E., Balankin, A., \& Resenos, E. (2009). Enfoque fractal aplicado en la administración. Investigación administrativa, 38(104), 43-57.

Guzmán-Aguilar, L. (2017). El diseño de un método analítico para el estudio del comportamiento del capital humano en la toma de decisiones empresariales, Págs. 90.

Iturriaga, R., \& Jovanovich, C. (2014). Fractales, economía y empresas. TRIM: revista de investigación multidisciplinar, (7), 5-23.

Iwamoto, H., \& Takahashi, M. (2015). A Quantitative Approach to Human Capital Management. Procedia-Social and Behavioral Sciences, 172, 112-119.

Mandelbrot, B.B. (1983). The fractal geometry of nature (Vol. 173). Macmillan.

Mandelbrot, B.B. (1997). Self-similarity and panorama of self-affinity. In Fractals and Scaling in Finance (pp. 146-197). Springer New York. Retrieved from http://link.springer.com/10.1007/978-1-4757-2763-0

Martínez, V.J. (1999). Is the universe fractal?. Science, 284(5413), 445-446.

Morales-Acoltzi, T., la Rosa-Orea, D., Medel-Rojas, A., \& Ramírez, J.F. (2015) Caracterización de Series de Tiempo de Datos Lluvia Diaria de la Estación Apizaco. Tlaxcala: Morfología Matemática.

Pérez, J.A. (2000). Música fractal: el sonido del caos. Departamento de Lenguajes y Sistemas Informáticos, Universidad de Alicante, Alicante.

Pestana, J.V. (1999). Fractalidad y comportamiento psicosocial. XXVII Congreso Interamericano De Psicología, Caracas-Venezuela. Retrieved from http://diposit.ub.edu/dspace/bitstream/2445/9625/1/CIP99_DD-UB.pdf

Vivas Miranda, J.G., García Chomiczak, S., \& Paz González, A. (1999). Teoría fractal y efecto de cambio de escala: aplicación al estudio de la porosidad del suelo.

Williams, G.P. (1997). Chaos theory tamed. Joseph Henry Press.

Yale University. (2016) Fractal Geometry. Recuperado el 18 de diciembre de 2016. Retrieved from http://users.math.yale.edu/public_html/People/frame/Fractals/ 